\section{Prevalence of keratinophilic fungi in public park soils of Mumbai, India}

\author{
Sunil Kumar Deshmukh, \\ Shilpa Amit Verekar \\ Department of Natural Products, \\ Piramal Healthcare Ltd., Mumbai, India
}

\section{Abstract}

The parks of Mumbai are frequently visited by local residents every morning and evening. However, there are no reports on the occurrence of keratinophilic fungi in these areas. The purpose of this research was to study the occurrence of keratinophilic fungi in the public parks of Mumbai. One hundred soil samples were collected from five public parks: Kamla Nehru Park, Powai Garden, CD Deshmukh Garden, Five Gardens and Chota Kashmir. Keratinophilic fungi were isolated by the hair baiting technique using human hair as keratin bait. The cultures were identified using macroand micro-morphological features. Identification was also confirmed by the BLAST search of sequences of the ITS1-5.8S-ITS2 rDNA region against the NCBI/Genbank data and compared with deposited sequences. The ability of these fungi to use human hair was also evaluated by release of protein in liquid media. A total of 75 strains of keratinophilic fungi were recovered from 100 (75.0\%) soil samples. The isolated fungi were composed of eleven species of eight genera: Arthrographis kalrae, Auxarthron conjugatum, Chrysosporium indicum, C. queenslandicum, C. zonatum, Gymnascella dankaliensis, G. hyalinospora, Microsporum gypseum (15.0\%), Myriodontium keratinophilum, Trichophyton mentagrophytes and Uncinocarpus reesii. These fungi can release $148.8-307.6 \mu \mathrm{g} / \mathrm{mL}$ protein in liquid media when grown on human hair in shake flask culture and also decompose 16.2-38.6\% of human hair after four weeks of incubation. Our study indicates that keratinophilic fungi are to be found in the soils of various public parks in Mumbai and that human hair can be a source of pathogenic fungi.

\section{Introduction}

Keratinophilic fungi are an ecologically important group of fungi that decompose one of the most abundant and highly stable animal proteins on earth, keratin, which they use as a nutrient substrate for growth. The distribution of these fungi depends on different factors, including the vitally important human and/or animal presence. ${ }^{1}$ Some of these fungi are well-known dermatophytes and are known to cause superficial cutaneous infections (dermatophytoses) of keratinized tissues (skin, hair and nails) of humans and animals. Mycotic infection is reported throughout the world and is extremely contagious. ${ }^{2}$ The occurrence of dermatophytes in soil was reported for the first time by Vanbreuseghem ${ }^{3}$ using the hair bait technique. Since then, studies on the isolation of keratinophilic fungi from soil have been investigated throughout the world. ${ }^{4-8}$

Mumbai (18 58N, $7351 \mathrm{E})$ is the financial capital of India with a population of about 10 million. It has a tropical climate with a high level of humidity. Its coastal and tropical location ensures moderate temperatures throughout the year, with an average temperature of $27.2^{\circ} \mathrm{C}$ and average precipitation of $242.2 \mathrm{~cm}$ (95.35 inches). ${ }^{9}$ This type of climate favors the growth of fungi. There have been some reports from Mumbai of dermatophytic infections. ${ }^{10-11}$ In previous studies, we have attempted to examine whether soils of salt pan, beaches and caves are a reservoir of these fungi. ${ }^{12-14}$

The public parks in Mumbai are frequently visited by local residents. Some areas of these parks are used by children as a playground. Some residents bring their pets to the park. These parks are also often invaded by animals such as cows, bullocks, pigs, cats and rats. Local birds are common to these parks: sparrow (Passer domesticus), pigeon (Columba livia domestica), dove (Streptopelia risoria), crow (Corvus brachyrhynchos), parrot (Psittacula krameri) and myna (Acridotheres tristis). Human activity may contribute to the keratinic material to be found in the soil. Transit animals leave organic residues which may contaminate the soil with keratinous debris and can provide reservoirs for fungi. It would, therefore, be important to analyze and identify the mycoflora of public parks in order to evaluate the extent of the diffusion of keratinophilic fungi in these environments and the resultant health risk.

\section{Materials and Methods}

One hundred soil samples were collected from five public parks in Mumbai: Kamla Nehru Park, Powai Garden, CD Deshmukh Garden, Five Gardens and Chota Kashmir from March 2008 to February 2009 (Table 1). The samples were collected from the superficial layer of soil at a depth not exceeding $3-5 \mathrm{~cm}$ and placed in sterile polyethylene bags, brought to the laboratory, and stored at $15^{\circ} \mathrm{C}$ for a maximum of two weeks if not processed promptly. Soil from the gardens is mostly
Correspondence: Sunil Kumar Deshmukh, Department of Natural Products, Piramal Healthcare Limited, 1 Nirlon Complex, Off Western Express Highway, Near NSE Complex, Goregaon (East), Mumbai 400 063, India.

Tel. +91.22.3081.8819 - Fax: +91.22 .3081 .8703 . E-mail: sunil.deshmukh@piramal.com

Key words: India, keratinophilic fungi, public parks, soil fungi, Mumbai.

Acknowledgment: the authors are grateful to Dr. Somesh Sharma, CSO, Dr. H. Sivaramakrishnan, President, Piramal Healthcare Ltd., for their support in this study.

Conflicts of interest: the authors declare no potential conflicts of interest.

Contributions: SKD, conceived the study, collected the soil samples, performed all the experiments, analyzed the data, and wrote the manuscript; SAV, conceived the study, performed all the experiments, analyzed the data, and wrote the manuscript.

Received for publication: 31 October 2011.

Revision received: 18 January 2012.

Accepted for publication: 8 February 2012.

This work is licensed under a Creative Commons Attribution NonCommercial 3.0 License (CC BYNC 3.0).

(C) Copyright S.K. Deshmukh and S.A.Verekar, 2012 Licensee PAGEPress, Italy

Microbiology Research 2012; 3:e6

doi:10.4081/mr.2012.e6

manure and litter, and soil $\mathrm{pH}$ varied from 6.5 to 8.5. Half decomposed feathers and hair (both from human and animal origin) were also found in garden soil.

Keratinophilic fungi were isolated by the hair baiting technique of Vanbreuseghem ${ }^{3}$ using human hair as keratin bait. For this purpose, sterile petri dishes half-filled with the soil samples and moistened with sterile water were baited by burying sterile human hair in the soil. These dishes were incubated at room temperature $\left(28 \pm 1^{\circ} \mathrm{C}\right)$ and examined daily from day 5 for fungal growth over a period of four weeks. After observing the growth under a stereoscopic binocular microscope, isolates were cultured on Sabouraud's dextrose agar supplemented with chloramphenicol $(50 \mathrm{mg} / \mathrm{L})$ and cycloheximide (500 mg/L).

Identification of these fungi was based on the monographs of Sigler and Carmichael, ${ }^{15}$ Oorchschot, ${ }^{16}$ Currah, ${ }^{17}$ Arx von, ${ }^{18}$ and Cano and Guarro ${ }^{19}$ using macro- and micro-morphological features.

Molecular characteristics of the cultures were studied by determination of their DNA 
sequences of the ITS1-5.8S-ITS2 region. Genomic DNA was extracted by the miniprep protocol of Lee and Taylor. ${ }^{20}$ The ITS1-5.8S-ITS2 rDNA was amplified using primers ITS1 and ITS4 as the forward and reverse primers, respectively, as described by White et al. ${ }^{21}$ and followed by Deshmukh and Verekar. ${ }^{6}$ The final products were analyzed by electrophoresis on $1.2 \%$ agarose (Sigma). The PCR products were purified using Qiagen Gel extraction kit (CAT No. 28704) and the PCR products of expected size were sequenced using ITS1 and ITS4 primers in an Applied Biosystem 3730 DNA analyzer at MWG, Bangalore, India. A BLAST ${ }^{22}$ search was made of the sequences against the NCBI/Genbank data and compared with deposited sequences for identification purposes.

\section{Substrate decomposition}

The substrate decomposition and protein released into the medium from human hair was monitored using the procedures set out by Lowry et al., ${ }^{23}$ and Deshmukh and Agrawal. ${ }^{24}$ Protein determinations from filtrates were carried out after four weeks of incubation. The developing color was read at $660 \mathrm{~nm}$ on a Shimadzu UV-VIS spectrophotometer. Freshly prepared human albumin serum was used as the standard. The results of protein determinations were expressed as net values, i.e. the measured value in the test sample minus the sum of values of keratin and fungus controls of 11 isolates (Table 1). Experimental values are expressed as mg of protein per mL of supernatant. All the experiments were carried out in triplicate at $28^{\circ} \pm 1^{\circ} \mathrm{C}$ with appropriate controls. The rate of hair decomposition was determined using the method of Chester and Mathison. ${ }^{25}$

\section{Results and Discussion}

The results of the isolations are presented in Table 1. They show that out of 100 samples only 75 yielded keratinophilic fungi which were categorized into 11 species of 8 genera:. Arthrographis kalrae (3.0\%), Auxarthron conjugatum (2.0\%), Chrysosporium indicum (26.0\%), C. queenslandicum (6.0\%), C. zonatum (5.0\%), Gymnascella dankaliensis (7.0\%), G. hyalinospora (3.0\%), Microsporum gypseum (15.0\%), Myriodontium keratinophilum (1.0\%), Trichophyton mentagrophytes (4.0\%) and Uncinocarpus reesii (3.0\%).

All the eleven strains yielded unique PCR amplification. The sequences of the ITS1- 5.8SITS2 rDNA region for the eleven strains were from 528 bp to 680 bp. Myriodontium keratinophilum and Trichophyton mentagrophytes were the smallest and the largest, respectively. The other species showed a product size of approximately $600 \mathrm{bp}$. There was considerable difference in the sequence data of the eleven strains analyzed. The data were also compared with sequences deposited in the NCBI/Genbank for identification purposes. The ITS data of the isolated strains were identical to the ITS data of Arthrographis kalrae (AB116536.1), Auxarthron conjugatum (AJ608967.1), Chrysosporium indicum (AJ005369.1), C. queenslandicum (AB219228.1), C. zonatum (AB219229.1), Gymnascella dankaliensis (AY304514), G. hyalinospora (AF129853.1), Microsporum gypseum (JN134130.1), Myriodontium keratinophilum (EU925387.1), Trichophyton mentagrophytes (HQ014707.1) and Uncinocarpus reesii (AB361653.1).

Chrysosporium indicum (26.0\%) was found to be the most dominating species followed by
M. gypseum. Chrysosporium indicum was reported from India's plains in various studies and dominates Indian soil mycobiota because it is adapted to warmer conditions. ${ }^{7,26-28}$ Microsporum gypseum, a well-known geophilic dermatophyte, had shown a frequency of $15.0 \%$, it has also been reported from Indian plains. ${ }^{29-}$ ${ }^{31}$ Gymnascella dankaliensis frequency followed that of $M$. gypseum at 7.0. Another species of Gymnascella was $G$. hyalinospora (3.0\%). Both these cultures were reported from soils of Orissa by Roy et al., ${ }^{32}$ and from Kerala by Deshmukh. ${ }^{33}$ Gymnascella dankaliensis was also reported from caves around Mumbai, India. $^{14}$

Chrysosporium queenslandicum (6.0\%) was the next dominating species of Chrysosporium after $C$. indicum followed by $C$. zonatum (5.0\%). Various species of Chrysosporium have been reported from Indian soils. ${ }^{34-36}$ Other species of fungi were Auxarthron conjugatum (2.0\%) and Myriodontium keratinophilum (1.0 \%). Auxarthron conjugatum was reported from India's plains in various studies ${ }^{37-38}$ and Myriodontium keratinophilum was reported from pigeon feathers from Maharashtra ${ }^{39}$ and also from the soils used in mud houses in Khammam, India. ${ }^{40}$

In the present study, we found Arthrographis kalrae in $3.0 \%$ of soil samples and this is reported in soils from various parts of world..$^{15}$ Similarly, Uncinocarpus reesii was found in $3.0 \%$ of soil samples only; Ajello and Padhye ${ }^{41}$ isolated it from the nesting sites of the Galapagos Islands, it has also been isolated from Chilka Lake, which is the largest saline lake in India, ${ }^{42}$ and from salt pan soils of Mumbai. ${ }^{12}$ Regarding the dermatophytes, we found Trichophyton mentagrophytes besides $M$.

Table 1. Distribution of keratinophilic fungi from public park soil samples, their proteolytic ability and \% decomposition of human hair.

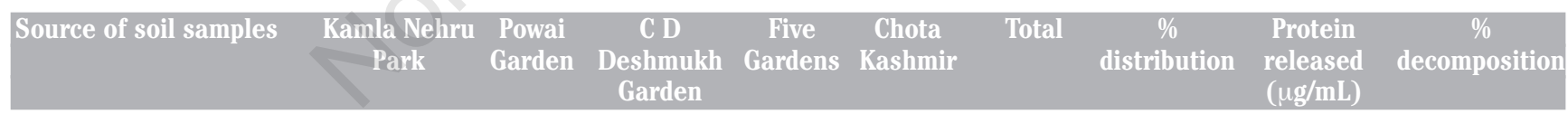

\begin{tabular}{|c|c|c|c|c|c|c|c|c|c|}
\hline No. of samples examined & 20 & 20 & 20 & 20 & 20 & 100 & & & \\
\hline No. of samples positive & 14 & 16 & 15 & 14 & 16 & 75 & & & \\
\hline Distribution (\%) & 56 & 64 & 60 & 56 & 64 & 75 & & & \\
\hline Arthrographis kalrae & 2 & 1 & - & - & - & 3 & 3 & 185.8 & 20.1 \\
\hline Auxarthron conjugatum & - & - & - & 2 & - & 2 & 2 & 127.4 & 16.2 \\
\hline Chrysosporium indicum & 7 & 5 & 6 & 3 & 5 & 26 & 26 & 164.8 & 24.4 \\
\hline Chrysosporium queenslandicum & 2 & 1 & 1 & 1 & 1 & 6 & 6 & 216.7 & 27.2 \\
\hline Chrysosporium zonatum & 1 & 2 & - & 2 & - & 5 & 5 & 246.4 & 28.2 \\
\hline Gymnascella dankaliensis & - & - & 2 & 3 & 2 & 7 & 7 & 192.7 & 22.4 \\
\hline Gymnascella hyalinospora & - & 1 & - & - & 2 & 3 & 3 & 168.6 & 20.2 \\
\hline Microsporum gypseum complex & 1 & 3 & 4 & 3 & 4 & 15 & 15 & 288.9 & 32.6 \\
\hline Myriodontium keratinophilum & - & 1 & - & - & - & 1 & 1 & 156.8 & 18.8 \\
\hline Trichophyton mentagrophytes & 1 & 1 & 1 & - & 1 & 4 & 4 & 307.6 & 38.6 \\
\hline Uncinocarpus reesii & - & 1 & 1 & - & 1 & 3 & 3 & 148.8 & 18.8 \\
\hline Total & 14 & 16 & 15 & 14 & 16 & 75 & 75 & & \\
\hline
\end{tabular}


gypseum in $4.0 \%$ of soil samples. Trichophyton mentagrophytes has been reported in Indian soils in various studies. . $^{7,29,30,34,36}$

The range of keratinolytic activity was expressed by protein release and percentage of decomposition of human hair. The release of protein ranges from a maximum of 307.6 $\mu \mathrm{g} / \mathrm{mL}$ by $T$. mentagrophytes and a minimum of $148.8 \mu \mathrm{g} / \mathrm{mL}$ by $U$. reesii after four weeks of incubation. A similar pattern was observed in percentage of decomposition of human hair. Trichophyton mentagrophytes decomposes a maximum of $38.6 \%$ of human hair after four weeks of incubation while minimum decomposition was observed in the case of $U$. reesii.

The prevalence of these fungi in garden soils and their keratinolytic activity is of importance for their pathogenic potential and has been confirmed in several investigations in different parts of the world. For example, Chrysosporium zonatum was reported to cause disseminated infection in a patient with chronic granulomatous disease. ${ }^{43}$ In Japan, $C$. zonatum strains were isolated from bronchial lavage from a female in Chiba and from a male in Kyushu. Both patients presented pulmonary cavity sites. ${ }^{44}$ Chrysosporium tropicum was reported from comb lesion in two different breeds of chicken in India. ${ }^{45}$ Neoarachnotheca keratinophila (teleomorph Myriodontium keratinophilum) have been reported to cause sinusitis. ${ }^{46}$ There are reports of disseminated infections due to $C$. queenslandicum in garter snakes; ${ }^{47}$ Gymnascella dankaliensis was reported from superficial infections in human beings, ${ }^{48}$ and Iwen et al., ${ }^{49}$ isolated Gymnascella hyalinospora from invasive pulmonary infection in a patient with acute myelogenous leukemia. Similarly, Lysková ${ }^{50}$ isolated Chrysosporium queenslandicum, C. sulfureum, C. tropicum, Malbranchea pulchella, Myriodontium keratinophilum from infections of the skin and nails of patients in the Moravian-Silesian Region (Czech Republic). Arthrographis kalrae is a documented etiological agent of mycetoma, ${ }^{51}$ photophobia in a contact lens wearer, ${ }^{52}$ sinusitis and meningitis in an AIDS patient, ${ }^{53}$ sinusitis and ophthalmitis in a healthy individual following trauma to the eye. ${ }^{54}$ Thus, these fungi may be regarded as opportunistic pathogens.

Our study has confirmed that these fungi are to be found in public gardens of Mumbai. On the one hand, they may be playing an important role in decomposing the keratinic matter deposited in these areas but on the other they may be a source of infection to the people visiting the public gardens of this densely populated city.

\section{References}

1. Deshmukh SK, Verekar SA. The occurrence of dermatophytes and other keratinophilic fungi from the soils of Himachal Pradesh (India). Czech Mycol 2006;58:117-24.

2. Hedayati MT, Mohseni-Bandpi A, Moradi S. A survey on the pathogenic fungi in soil samples of potted plants from Sari hospitals, Iran. J Hosp Infect 2004;58:59-62.

3. Vanbreuseghem R. Technique biologique pour 1' isolement des dermatophytes du sol. Ann Soc Belge Med Trop 1952;32:173-8.

4. Shadzi S, Chadeganipour M, Alimoradi M. Isolation of keratinophilic fungi from elementary schools and public parks in Isfahan, Iran. Mycoses 2002;45:496-9.

5. Ali-Shtayeh MS, Khaleel TKh, Jamous RM. Ecology of dermatophytes and other keratinophilic fungi in swimming pools and polluted and unpolluted streams. Mycopathologia 2002;156:193-205.

6. Papini R, Mancianti F, Grassotti G, Cardini G. Survey of keratinophilic fungi isolated from city park soils of Pisa, Italy. Mycopathologia 1998;143:17-23.

7. Deshmukh SK, Verekar SA. Keratinophilic fungi from the vicinity of meteorite soils of Lonar (India). Mycopathologia 2006;162: 303-6.

8. Zaki SM, Mikami Y, El-Din AA, Youssef YA. Keratinophilic fungi recovered from muddy soil in Cairo vicinities, Egypt. Mycopathologia 2005;160:245-51.

9. Rohli RV, Vega AJ. Climatology (illustrated ed.) Jones and Bartlett Publishers, 2007, pp 267.

10. Mehta JP, Deodhar KP, Mehta VR, Chaphekar PM. A study of Dermatophytoses in Bombay. Indian $\mathrm{J}$ Pathol Microbiol 1977;20:23-31.

11. Mathur M, Baradkar VP, De A, et al. Dermatomycosis caused by common and rare fungi in Mumbai. Indian $\mathrm{J}$ Dermatol Venereol Leprol 2008;4:402-3.

12. Deshmukh SK. Isolation of dermatophytes and other keratinophilic fungi from the vicinity of salt pan soils of Mumbai (India). Mycopathologia 2004;157:265-7.

13. Deshmukh SK. Keratinophilic fungi isolated from soils of Mumbai, India. Mycopatholo-gia 1999;146:115-6.

14. Verekar SA, Deshmukh SK. Incidence of keratinophilic fungi from caves around Mumbai, Maharashtra (India). Journal of Basic and Applied Mycology 2006;5:62-4.

15. Sigler L, Carmichael JW. Taxonomy of Malbranchea and some other hyphomycetes with arthroconidia. Mycotaxon 1976;4: 349-488.

16. Van Oorschot CAN. A revision of Chrysosporium and allied genera. Stud Mycol 1980;20: 1-89.
17. Currah RS. Taxonomy of Onygenales: Arthrodermaceae, Gymnoascaceae, Myxotrichaceae and Onygenaceae. Mycotaxon 1985;24:1-216.

18. Arx von JA. The ascomycetes genus Gymnoascus. Persoonia 1986;13:173-83.

19. Cano J, Gurrao J. The genus Aphanoascus. Mycological Research 1990;94:355-77.

20. Lee SB, Taylor JW. Isolation of DNA from fungal mycelium, single cells In: MA Innis, DH Gelfand, JJ Sninsky, TJ White (eds.) PCR protocols: a guide to methods and applications. Academic Press San Diego, California, USA, 1990, p 282-7.

21. White TJ, Bruns T, Lee S, Taylor J. Amplification and direct sequencing of fungal ribosomal RNA genes for phylogenetics. In: A Innis, DH Gelfand, JJ Sninsky, TJ White (eds.) PCR protocols: a guide to methods and applications. Academic Press, San Diego, California, USA, 1990, p 315-22.

22. Altschul SF, Gish W, Miller W, et al. Basic local alignment search tool. J Mol Biol 1990;215:403-10.

23. Lowry $\mathrm{OH}$, Rosebrough NJ, Farr AL, Randall RJ. Protein measurement with the FolinPhenol reagents J Biol Chem 1951;193:26575.

24. Deshmukh SK, Agrawal SC. Degradation of human hair by some dermatophytes and other keratinophilic fungi. Mykosen 1985; 28:463-6.

25. Chester CGC, Mathison GE. The decomposition of wool keratin by Keratinomyces ajelloi. Sabouraudia 1963;2:225-37.

26. Singh CJ, Geetha-Singh B, Singh BS. Keratinophilic fungi of Ghana birds sanctuary Bharatpur (Rajasthan). Advances in Plant Sciences 1994;7:280-91.

27. Katiyar S, Kushwaha RKS. Human hair colonizing fungi in water sediments of India. Mycopathologia 2001;152 :81-4.

28. Saxena P, Kumar A, Shrivastava JN. Diversity of keratinophilic mycoflora in the soil of Agra (India). Folia Microbiol 2004;49:430-4.

29. Garg AK. Isolation of dermatophytes and other keratinophilic fungi from soils in India. Sabouraudia 1966;4:259-64.

30. Ramesh VM, Hilda A. Incidence of keratinophilic fungi in the soil of primary schools and public parks of Madras City, India. Mycopathologia 1998-99;143:139-45.

31. Ranganathan S, Balajee SA. Microsporum gypseum complex in Madras, India. Mycoses 2000;43:177-80.

32. Roy K, Ghosh GR, Dutta SK. Keratinophilic fungi and prevalence of dermatomycoses in Orissa, India. Sabouraudia 1972;10:218-29.

33. Deshmukh SK. Incidence of Keratinophilic fungi from selected soils of Kerala state (India). Mycopathologia 2002;156:177-81.

34. Randhawa HS, Sandhu RS. A survey of soil inhabiting dermatophytes and related ker- 
atinophilic fungi of India. Sabouraudia $1965 ; 4: 71-9$.

35. Kushwaha RKS, Agarwal SC. Some keratinophilic fungi and related dermatophytes from soils. Proc Indian Natn Sci Acad 1976;42:102-10.

36. Deshmukh SK. Incidence of dermatophytes and other keratinophilic fungi in the glacier bank soils of Kashmir (India). Mycologist 2002;16:165-7.

37. Jain PC, Agrawal SC. Some addition to Indian Malbranchea. Kavaka 1979;7:69-72.

38. Deshmukh SK, Verekar SA, Shrivastav A. Prevalence Of Keratinophilic Fungi In Selected Soils Of Ladakh (India). Natural Sciences 2010;2:1147-52.

39. Deshmukh SK. Keratinophilic fungi from feathers of pigeon in Maharashtra India. Mycoses 2004;47:213-5.

40. Deshmukh SK, Verekar SA. Keratinophilic fungi from the soils of mud houses of Khammam district of Andhra Pradesh (India). Kavaka 2005;33:57-9.

41. Ajello L, Padhye AA. Keratinophilic fungi of the Galapagos Islands. Mykosen 1974;17: 239-43.

42. Ghosh GR, Bhatt S. Keratinophilic fungi from Chilka Lake-side soil Orissa (India). Indian Journal of Microbiology 2000;40:247-
54.

43. Roilides E, Sigler L, Bibashi E, et al. Disseminated infection due to Chrysosporium zonatum in a patient with Chronic granulomatous disease and review of nonAspergillus fungal infection in patients with this disease. J Clin Microbiol 1999; 37:18-25.

44. Sigler L, Flis AL, Carmichael JW. The genus Uncinocarpus (Onygenaceae) and its synonym Brunneospora: new concepts, combinations and connections to anamorphs in Chrysosporium, and further evidence of relationship with Coccidioides immitis. Canad J Bot 1998;76:1624-36.

45. Saidi SA, Bhatt S, Richard JL, et al. Chrysosporium tropicum as a probable cause of mycoses of poultry in India. Mycopathologia 1994;125:143-7.

46. Maran AGD, Kwong K, Milne LJR, Lam BD. Frontal sinusitis caused by Myriodontium keratinophilum. Brit Med J 1985;20:207.

47. Vissiennon T, Schuppel KF, Ullrich E, Kuijpers AF. Case report. A disseminated infection due to Chrysosporium queenslandicum in a garter snake (Thamnophis). Mycoses 1999;42:107-10.

48. De Hoog GS, Guarro J. Atlas of clinical fungi. Centraalbureau voor Schimmelcul- tures. Baarn, The Neatherland, 1995.

49. Iwen PC, Sigler L, Tarantolo S, et al. Pulmonary infection caused by Gymnascella hyalinospora in a patient with acute mycelogenous leukemia. Journal of Clinical Microbiology 2000;38:375-81.

50. Lysková P. Saprotrophic microscopic fungi and dermatophytes accompanying infections of the skin and nails of patients in the Moravian-Silesian Region (Czech Republic). Czech Mycol 2007;59:125-37.

51. Degavre B, Joujoux JM, Dandurand M, Guillot B. First report of mycetoma caused by Arthrographis kalrae: successful treatment with itraconazole. J Am Acad Dermatol 1997;37:318- 20.

52. Perlman EM, Binns L. Intense photophobia caused by Arthrographis kalrae in a contact lens-wearing patient. Am J Ophthalmol 1997;123:547-49.

53. Chin-Hong PV, Sutton DA, Roemer M, et al. Invasive fungal sinusitis and meningitis due to Arthrographis kalrae in a patient with AIDS. J Clin Microbiol 2001;39:804-7.

54. Xi L, Fukushima K, Lu C, et al. First case of Arthrographis kalrae ethmoid sinusitis and ophthalmitis in the People's Republic of China. J Clin Microbiol 2004;42:4828-31. 